\title{
La Cesión de créditos en el Sistema Financiero
}

\section{The Assignment of Credits in the Financial System}

Mario Nugent N'Egrillo * http://orcid.org/0000-0002-3457-3742

http://dx.doi.org/10.21503/lex.v19i28.2310

* Abogado en Derecho Corporativo. Magister en Derecho Empresarial en la Universidad de Lima. Catedrático de la Universidad de Lima y Universidad San Martín de Porres en los cursos de Derecho Comercial II y III, Derechos Reales, Derecho Financiero, y Derecho Monetario y Bancario. Decano de la Facultad de Derecho y Ciencia Política de la Universidad Alas Peruanas. Perú.

Correo electrónico: m_nugent@uap.edu.pe

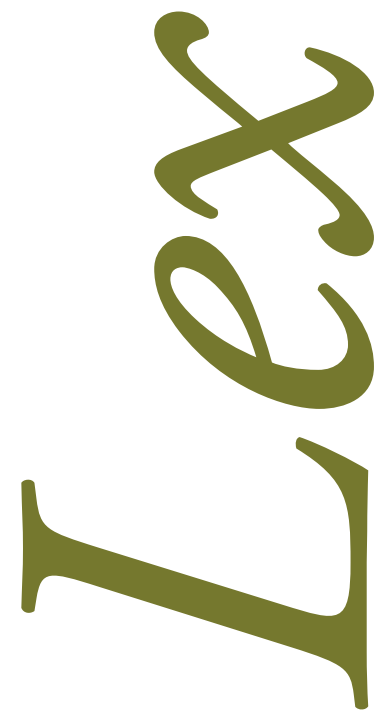




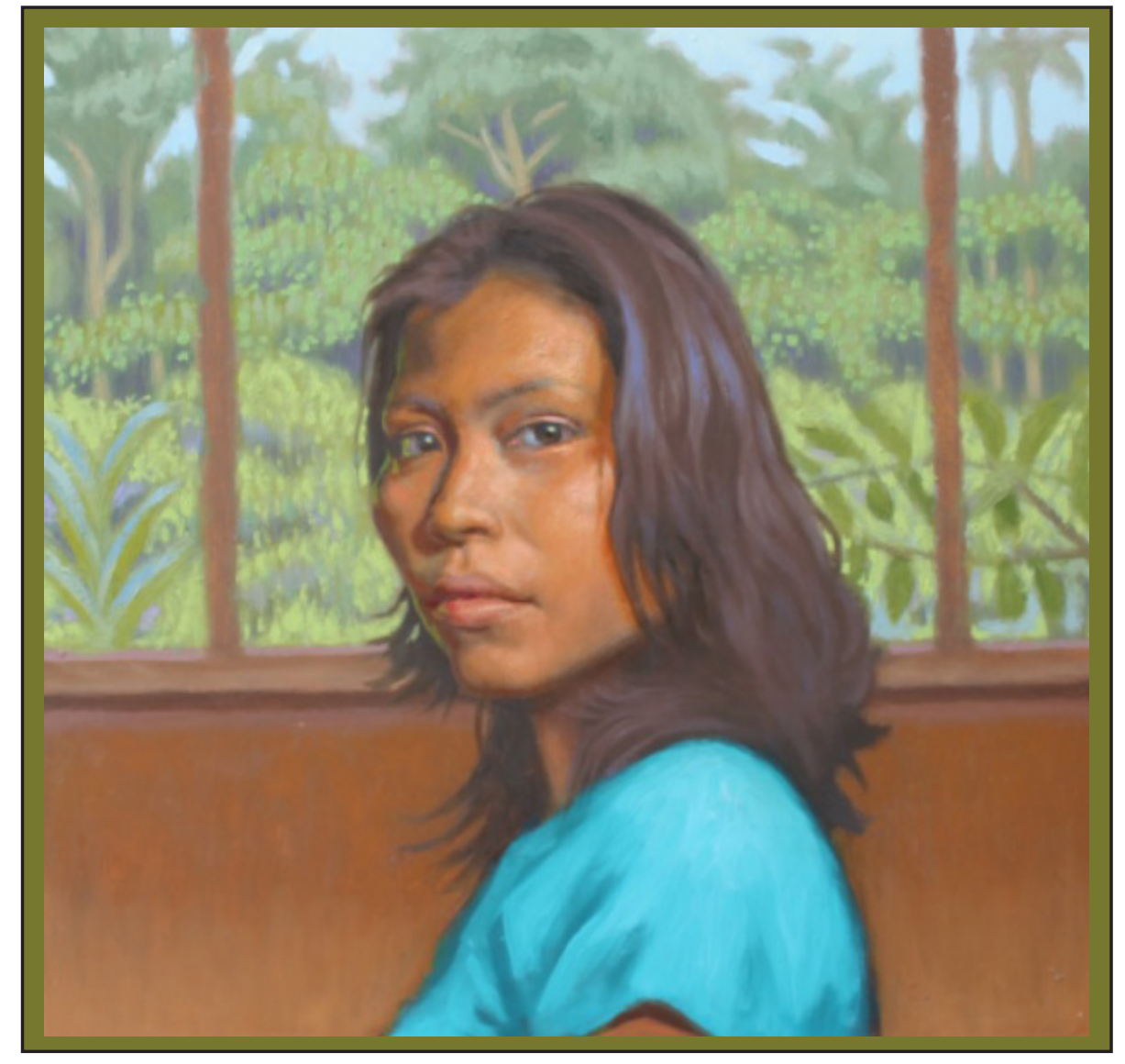

Pensando en ancestros. Óleo sobre madera, 31 x $31 \mathrm{~cm}$.

David Hewson (EEUU, 1966)

www.davidhewsonart.com 


\title{
RESUMEN
}

El presente trabajo analiza la problemática generada a partir de la apertura de mercados que hizo posible el otorgamiento de créditos de consumo sin mayores garantías lo que provocó el aumento de la morosidad y el incremento de riesgo crediticio. Esto obliga a las instituciones del sistema financiero a destinar tiempo y recursos para la recuperación de créditos. Frente a esta situación, surgieron las empresas especializadas en cobranzas que se constituyeron específicamente con esta finalidad y la figura de la cesión derechos y acciones de la cartera morosa como una herramienta necesaria para evitar la concentración de morosidad y el incremento del riesgo financiero, liberando a la institución financiera de la administración del riesgo. En este sentido adquiere gran importancia el contrato financiero de cesión de créditos en el que se busca transmitir en forma conjunta los derechos, acciones y privilegios, así como también las obligaciones a través de la unión del traslado de créditos y sus derechos implícitos. La cesión se hace entre el cedente y el cesionario, sin la intervención del cedido, lo único que se exige es una comunicación fehaciente al cedido de dicha cesión, sin necesidad de su consentimiento. En suma, se busca dar soluciones al tema investigado, sobre la necesidad de las empresas financieras de enajenar su cartera dentro de un marco atractivo legal, que permita dar solución a corto plazo, cumpliendo con los mecanismos que establece el régimen jurídico vigente.

Palabras clave: cesión de créditos, riesgo crediticio, empresa de factoring, análisis de recuperación, administración del riesgo - sistema financiero.

\begin{abstract}
This paper analyzes the problems generated by the opening of markets that made it possible to grant consumer loans without greater guarantees, which caused an increase in delinquencies and an increase in credit risk. This forces the institutions of the financial system to allocate time and resources for the recovery of credits. Faced with this situation, companies specialized in collections emerged that were specifically established for this purpose and the figure of the transfer of rights and shares of the delinquent portfolio as a necessary tool to avoid the concentration of delinquency and the increase in financial risk, freeing up the financial institution of risk management. In this sense, the financial contract for the assignment of credits, which seeks to jointly transmit the rights, shares and privileges, as well as the obligations through the union of the transfer of credits and their implicit rights, acquires great importance. The assignment is made between the assignor and the assignee, without the intervention of the assignee, the only thing that is required is a reliable communication to the assignee of said assignment, without the need for their consent. In short, it seeks to provide solutions to the investigated issue, about the need for financial companies to dispose of their portfolio within an attractive legal framework, which allows a short-term solution, complying with the mechanisms established by the current legal regime.
\end{abstract}

Key words: loan assignment, credit risk, factoring company, financial recovery analysis, risk management-system. 


\section{INTRODUCCIÓN}

Hoy en día con la evolución del comercio, y con la apertura de los mercados internacionales, se han generados nuevas figuras jurídicas para lograr reducir los riesgos financieros, asimismo con la economía de mercados y la gran competencia en la colocación de créditos entre las empresas financieras, en el Perú se otorgaron muchas facilidades crediticias al público en general, sin mayores garantías que un pagaré y/o un aval, de esa manera las empresas del Sistema Financiero ofrecieron con la apertura de mercados y la economía de mercado créditos de consumo, de esa manera la Administración del Riesgo cada vez va escapando del objeto Instituciones del Sistema Financiero en sí, ya que hace destinar tiempo y dinero a la recuperación de créditos, incrementando el riesgo crediticio; y por ello desde hace un tiempo atrás se encarga dicha labor a empresas especializadas en cobranzas constituidas especialmente para la recuperación de créditos, tales como Estudios de Abogados, Empresas de Cobranzas y otras.

Es de resaltar que las Circulares y Oficios Circulares que emite la Superintendencia de Banca y Seguros sobre el tema de Provisiones, ha generado que la Banca de Consumo en especial, que se dedica a ofrecer productos a personas de bajo extracto social (Sector C y D), y que generalmente ocasiona un alto índice de morosidad, eventualmente un porcentaje de su cartera se castigue, generando más costos al Banco a través de las pérdidas de las operaciones de crédito, en vista de ello, estas empresas cada vez tienen necesidades de transferir su cartera a terceros, trasladando la totalidad del riesgo y dedicándose principalmente a ofrecer productos dentro de una política crediticia competitiva y de acuerdo a las operaciones que lo faculte la Superintendencia de Banca y Seguros.

Con la cesión y/o transferencia de cartera se intercambia la posición contractual, asumiendo la cedida, los derechos, acciones y privilegios de la cedente, en tal sentido produce en el cedente la obligación de colocar al cesionario en la misma posición contractual, la contraprestación del cedido es pagar un precio de acuerdo al análisis de valoración (tasación comercial) versus el tiempo de recuperación y gastos generales que se requieren para obtener la recuperación efectiva y total. Asimismo, del análisis de la actual Ley del Sistema Financiero (Ley 26702) ${ }^{1}$, estás empresas que adquieran cartera pueden encuadrarse, dependiendo de la reglamentación dentro de las empresas de Factoring.

1. Ley del Sistema Financiero (Ley 26702) 
La importancia que viene teniendo hoy en día la figura de la cesión de derechos y acciones de la cartera morosa, es una herramienta necesaria para evitar la concentración de morosidad, liberando al Banco de la Administración del Riesgo de cartera con más de 180 días de mora o con menor tiempo. Es por ello que las Empresas Bancarias requieren de aliviar la concentración de tales créditos con alto índice de morosidad.

Considero que la presente investigación tiene una importancia fundamental por ser un tema actual, vinculado con el Sistema Financiero. Las Instituciones Bancarias comúnmente se cuestionan que hacer con la cartera con retardo de pagos por parte de sus clientes, toda vez que la ejecución judicial para exigir el cumplimiento de las obligaciones generalmente retarda más de ocho meses, en vista de los problemas conocidos del actual Poder Judicial.

Resulta pues, un mecanismo de solución de rebajar la cartera de riesgos de los Bancos a un precio razonable para las partes negociantes (previo análisis de costo - beneficio).

La contribución de generar empresas que inviertan en este rubro, en base a grandes sumas de inversión para el pago por la compra de capital, infraestructura y contratación de personal.

Se desea conseguir con ello métodos de solución de las empresas financieras para con la cartera vigente y castigada que tiene fruto de la colocación de créditos, analizando que el riesgo se genera desde que se coloca el crédito. Además del beneficio que genera a mi persona al analizar este tipo de transacción comercial, los beneficiados son los Bancos, las empresas de administración de riesgos, nuestra casa de estudios y la comunidad jurídica nacional.

Ahora con la Ley del Sistema Financiero y el Reglamento de factoring, descuento y empresas de factoring a través de la Resolución SBS No1021-98 del 3 de octubre de 1998, se abren las puertas para desarrollar parcialmente otros negocios, como el factoring, en vista del crecimiento de riesgo en el mercado, sin embargo esta norma señala en su art. 2 “...las operaciones de factoring no podrán realizarse con instrumentos vencidos u originados en operaciones de financiamiento con empresas del sistema financiero...”

En consecuencia, pese a entender que dicha resolución ha restringido los alcances de la Ley (dado que esta no establece limitación alguna), no todas las empresas se podrían acoger a este modelo, con lo cual eventualmente se favorecerían las empresas de factoring al calificarse como exonerados de IGV por los servicios de factoring; no obstante, las operaciones de venta de cartera no se encuentran gravadas con el IGV, en la medida que se trata de documentos representativos de dinero, bien que no es considerado mueble de acuerdo con la Ley del Impuesto General a las Ventas.

El factoring consiste en la cesión de créditos mercantiles que en su participación reconoce a tres actores en el proceso: el cliente, el cesionario (empresa de factoring), y el deudor (persona o empresa que contrató el servicio o compra de bienes) a diferencia de la cesión de créditos, que a lo largo de este trabajo explicaré en que consiste. 
Se trata en buena cuenta en la venta de cuentas por cobrar a la compañía de factoring, la que realiza la cobranza de los créditos cedidos, por lo cual la empresa reduce sus costos operativos.

Además, eso le permite al cliente contar con una línea aprobada, lo que significa que en menos de 24 horas puede disponer de los fondos. Junto con ello mejora las ratios (promedio) de balance dado que disminuye la rotación de cuentas por pagar según destino y, a su vez, disminuye el leverage.

\section{NATURALEZA JURÍDICA DE LA CESIÓN DE CRÉDITOS}

Es un contrato financiero, en la cesión de créditos se busca transmitir en forma conjunta los derechos, acciones y privilegios, en ello también se encuentra las obligaciones a través de la unión del traslado de créditos y sus derechos implícitos, con el traslado de obligaciones. La cesión se debe hacer entre el cedente y el cesionario, sin la intervención del cedido, lo único que se exige es una comunicación fehaciente al cedido de dicha cesión, sin necesidad de su consentimiento, ni mucho menos.

En ello el cedente se transfiere la posición contractual a través de un acto jurídico de disposición a título singular sobre la relación jurídico contractual que constituye el contrato.

Los derechos de créditos u obligaciones, cualquiera sea su naturaleza, pueden variar objetivamente (la prestación sufre alguna alteración sin cambiar los sujetos de la obligación - fraccionamiento del pago, dación en pago), o subjetivamente (no varía la obligación por aumentar a un nuevo obligado como con un fiador solidario, subrogación o cesión).

Definir el concepto epistemológico de LA CESIÓN DE CRÉDITOS EN EL SISTEMA FINANCIERO, en ello encontramos las diferencias más trascendentes con otras figuras del derecho o con hechos o actos jurídicos que se presentan en el Sistema Financiero, conceptualizar a las partes intervinientes, describiendo cual es la acción que desempeńa en el tema de investigación.

Para definir la Naturaleza Jurídica podemos acentuar que es un contrato financiero y de colaboración complejo, pues con el concurre un arrendamiento de servicios como una comisión de cobro, una asunción de créditos y una asunción pro nuptio. Se le considera también en términos generales como una financiación.

Así, de acuerdo con Juan M. Farina ${ }^{2}$ estos tipos de contratos “... tuvieron su origen en Gran Bretaña, donde partió a la conquista de los Estados Unidos. Los norteamericanos no hicieron más que adueñarse de la fórmula, modificándola y añadiéndola algunas variantes, para desembocar finalmente en el new factoring..." que es una modalidad de ceder créditos.

Por analogía, este supuesto es parecido al descuento bancario, no definido por el Código de Comercio; pero si certeramente por el Código Civil Italiano, afirmando que descuento es el contrato

2. Juan M. Farina, Contratos Comerciales Modernos, (Buenos Aires, Argentina: Editorial Astra, B. Aires, 1993). 
mediante el cual el Banco, previa deducción del interés, anticipa al cliente el importe de un crédito no vencido contra terceros, mediante el importe de un crédito no vencido contra terceros, mediante la cesión, salvo buen fin, del crédito mismo.

\subsection{Origen y antecedentes de la cesión de créditos}

En la segunda mitad del siglo pasado existió la preocupación entre los juristas de encontrar una solución jurídica a la transmisión de obligaciones y créditos en un sólo acto jurídico, de los derechos y obligaciones emanados de un contrato jurídico entre los ańos 20 y 40 se produce un movimiento doctrinal que se preocupa al fondo del problema de la cesión de la relación contractual, que dio lugar al Código Civil Italiano de 1942 fue el primer cuerpo legal que sancionó legislativamente la cesión del contrato como figura jurídica. Luego en el Congreso de Derecho comparado realizado en Londres en 1950, se presentó como ponencia la cesión de derechos del contrato, lo que dio lugar a un auge impresionante, siendo unánime la opinión de su inclusión en los ordenamientos legales positivos.

\subsection{Definición}

A mi juicio es la transferencia de cartera en la que se intercambia la posición contractual, asumiendo la cedida los derechos, acciones y privilegios de la cedente, en tal sentido produce en el cedente la obligación de colocar al cesionario en la misma posición contractual, la contraprestación del cedido es pagar un precio de acuerdo al análisis de valoración versus el tiempo de recuperación y gastos generales que se requieren para obtener la recuperación efectiva y total.

La importancia que viene teniendo hoy en día la figura de la cesión de derechos y acciones de la cartera morosa, es una herramienta necesaria para evitar la concentración de morosidad, liberando al Banco de la Administración del Riesgo de cartera con más de 180 días de mora o con menor tiempo.

En nuestro Código Civil se encuadra en el art. 1435, definiéndolo que en los contratos con prestaciones no ejecutables total o parcialmente, cualquiera de las partes puede ceder a un tercero su posición contractual.

Se requiere que la otra parte preste su conformidad antes, simultáneamente, o después del acuerdo de cesión.

Si la conformidad del cedido hubiera sido prestada previamente al acuerdo entre el cedente y cesionario, el contrato sólo tendrá efectos desde que dicho acuerdo haya sido comunicado al cedido por escrito con fecha cierta.

Otros tratadistas lo configuran como un contrato, por el cual se instituye un tercero en la persona del acreedor original que le ha transmitido el crédito, convirtiéndose a su vez en acreedor. Es un simple cambio de acreedor frente al deudor. 
La cesión de créditos presenta la característica de no tener por objeto bienes, sino simplemente derechos, es decir; cosas inmateriales.

\subsection{Diferencias con otras figuras jurídicas}

La importancia que viene teniendo hoy en día la figura de la cesión de derechos y acciones de la cartera morosa, es una herramienta necesaria para evitar la concentración de morosidad, liberando al Banco de la Administración del Riesgo de cartera con más de 180 días de mora o con menor tiempo.

Las diferencias con la novación, subcontrato, contrato a favor de tercero, el assignment.

\subsubsection{La Novación}

Conforme a ello un nuevo sujeto activo o pasivo subentra en la relación obligatoria, aquí quedan modificados los lados activos y pasivos de la relación obligatoria, se precisan dos negocios, a diferencia de la Cesión de créditos.

\subsubsection{El Subcontrato}

En ambos se transfieren derechos y obligaciones emanados de los contratos básicos. Aquí se crea un contrato nuevo, distinto del básico, mientras que en la cesión busca que el cesionario entre en el contrato básico, ocupando la posición de parte. En el subcontrato el subcontratante tiene una duplicidad de relaciones, unas con el contratante en el contrato básico y otras con su contraparte en el subcontrato.

\subsubsection{Contrato a favor de tercero}

Es constitutivo mediante él se crea un nuevo derecho que no existía antes, existe un contrato bilateral celebrado entre el estipulante y el promitente, en virtud del cual éste se obliga en favor de un tercero; mientras que en la cesión intervienen tres partes.

\subsubsection{El Assignment}

Es el acto en virtud del cual se extingue el derecho del cedente a exigir al cedido el cumplimiento de su obligación y el cesionario adquiere tal derecho. es una cesión de créditos y no una cesión de posición contractual, ya que para que esta se realice es necesario que una nueva parte se sustituya en el foco de las relaciones legales con respecto a determinado contrato, asumiendo los derechos y obligaciones del cedente.

\subsection{Sujetos intervinientes}

\subsubsection{El cedente}

Es la parte que sale de la relación contractual, perdiendo su titularidad sobre los derechos y obligaciones que le corresponden según la relación jurídica creada en el contrato. Es el que cede los derechos y obligaciones que contiene el crédito. 


\subsubsection{El cesionario}

Es la parte que sustituye al cedente, entra en la relación obligacional. Es un tercero que asume la posición contractual del anterior.

\subsubsection{El cedido}

Esta es la parte que permanece en la relación nacida contractualmente, limitándose a permitir el cambio de sujetos entre el cedente y cesionario, su actitud es meramente pasiva aceptando la cesión ${ }^{3}$.

Sobre aspectos jurídicos de distintos contratos atípicos, ver E. Chulía Vicent, Bentrán Alandete ${ }^{4}$.

García Cruces 5 , sostiene que la necesidad de notificar al deudor, no tiene otra finalidad que la de lograr el conocimiento del deudor, una eficacia consultiva. Es importante tener en cuenta, que conforme al art. 1210, la cesión de derechos será inválida cuando tenga por objeto aquellas deudas en las que se hubiera prohibido expresamente. Pese a ello, en aplicación a la misma norma, si el factor actuó de buena fe por ignorar la prohibición, la cesión será válida.

2.5 - Derechos y obligaciones de las partes

Existen derechos y obligaciones entre el factor y el cliente.

Obligaciones del factor:

a) Adquirir los créditos que se originen de la manera y en las condiciones previstas contractualmente.

b) Pagar las facturas transferidas.

c) Otorgar anticipo de fondos, de acuerdo con lo acordado contractualmente.

d) Cobrar los créditos cuyos derechos se han subrogado.

e) Efectuar los servicios de facturación, contabilidad y demás convenidos.

f) Prestar la asistencia técnica y administrativa.

3. Los deudores no integran el contrato, pero son sujetos colaterales, ya que se le debe notificar de la cesión de créditos a fin de conocer quién es el nuevo acreedor de su deuda, a quien debe cancelar. No siendo necesario su consentimiento en aplicación del artículo 1206 del C.C.

4. E. Chulía Vicént, Beltrán Alandete, Aspectos jurídicos de contratos atípicos, (Barcelona. España: Editorial: José María Bosch Editor, 1998), pág. 25 y sgt.

5. José Antonio García Cruces Gonzáles, El Contrato de Factoring, (Ediciones Tecno, Madrid, 1990). 


\section{CARACTERÍSTICAS DE LA CESIÓN DE CRÉDITOS EN EL SISTEMA FINANCIERO}

-Es un contrato principal (ya que tiene autonomía propia y no depende de otro contrato).

-Es conmutativo (las partes al suscribir el contrato conocen los beneficios a recibir).

-Es un contrato consensual ya que se celebra con acuerdo de las partes.

-Es un contrato típico porque tiene regulación en nuestro ordenamiento jurídico.

-Es oneroso (las contraprestaciones son valuables monetariamente).

-Es un contrato literal (pues su mecanismo se basa en la cesión de derechos y en las cláusulas generales de contratación.

-Es un contrato conmutativo, por que las partes al contratar saben los resultados que se obtendrán de esa operación.

-Es un contrato de contenido flexible, ya que se puede estipular la prestación del servicio de gestión o cobro asumiendo los riesgos de la cobranza.

3.1 Requisitos para la compra de cartera

De acuerdo al art. 1207 del Código Civil, debe constar por escrito bajo sanción de nulidad, dicho elemento sirve de constancia de la cesión.

La cesión de crédito no puede efectuarse cuando se opone a la ley, a la naturaleza de la obligación o al pacto con el deudor.

\subsection{Formación del contrato}

La cesión y/o transferencia de cartera que con el mismo se intercambia la posición contractual, asumiendo la cedida los derechos, acciones y privilegios de la cedente, en tal sentido produce en el cedente la obligación de colocar al cesionario en la misma posición contractual, la contraprestación del cedido es pagar un precio de acuerdo al análisis de valoración versus el tiempo de recuperación y gastos generales que se requieren para obtener la recuperación efectiva y total. Asimismo, busco dar soluciones al tema investigado, sobre la necesidad de las empresas Financieras de enajenar su cartera dentro de un marco atractivo legal, que permita dar solución a corto plazo, cumpliendo con los mecanismos que establece el régimen jurídico vigente.

\subsection{Objeto del contrato}

El objeto del contrato es transferir y sacar del pasivo créditos de preferencia morosos (más de 120 días de mora en el pago) y ceder la posición contractual del crédito a favor del cesionario, financiando 
o pagando una contraprestación de acuerdo a una valuación de la cartera a ser transferida o a título gratuito, para que éste ejecute y/o recupere la deuda (administrando el riesgo transferido), en este caso el cedente tiene la obligación de comunicar fehaciente al cedido que el crédito que se le otorgó e incumplió ha sido transferido a un tercero.

\subsection{Efectos del contrato}

El principal efecto es la circulación de créditos de la relación jurídica creada por el contrato, o sea que el cesionario entra en vez del cedente en la relación crediticia, asumiendo el activo, pasivo, derechos, acciones y privilegios.

\subsubsection{Efectos entre le cedente y el cesionario}

El primer efecto es el intercambio de la posición contractual, asimismo, hay una obligación que deberá garantizarse la existencia y exigibilidad del crédito cedido, o no sujeta a saneamiento, salvo pacto que libere de responsabilidad por su incobrabilidad o gastos de cobranza que se generen.

\subsubsection{Efectos entre el cedente y el cedido}

El cedente queda liberado de todas las obligaciones que tiene con respecto al cedido, así como pierde todos los derechos que tenía sobre éste por razón del contrato.

\subsubsection{Efectos del cedido y cesionario}

El cedido y cesionario deberán cumplir con todas las obligaciones recíprocas estipuladas en el contrato. Existe además el derecho que adquiera el cedido de oponer al cesionario todas las excepciones nacidas del contrato original.

\subsection{Obligaciones de la Empresa Financiera cedente}

Dentro de las obligaciones es la de firmar los documentos sustentatorios de las acreencias a favor del cesionario, como son el contrato, el endoso de títulos valores, la comunicación al cedido que el crédito se transfirió a un tercero en forma fehaciente, y de ser el caso comunicar al juez en el estado del proceso de ejecución que se han cedido los derechos, acciones y privilegios del crédito materia de litis (en la obligación de dar suma de dinero).

Los Bancos transfieren en propiedad los títulos valores y documentos sustentatorios de acreencias (liquidaciones de saldo deudor), contratos de crédito, que conlleva la cesión de derechos y acciones de tales acreencias. En consecuencia, el nuevo titular y nuevo acreedor de las deudas respectivas es EL Cesionario, dichas acreencias y/o deuda de los clientes se mantendrá ligada a una obligación cuya naturaleza jurídica no varía ni se altera con ocasión de dicha cesión. 
Los importes considerados en los pagarés que son materia de la transferencia, están integrados por el capital e intereses provenientes de la actividad crediticia propio del giro del negocio del Banco. Ello implica que los intereses contenidos en dichos títulos valores constituyen la retribución por el servicio de financiamiento que otorgó el Banco a sus clientes. En ese sentido, cuando al Cesionario le ceden los derechos y acciones se entiende que es titular de los intereses que se devenguen en adelante a la compra.

De otro lado, desde el punto de vista tributario en lo que respecta a los intereses que devenguen los créditos, se debe mencionar que fueron pactados al amparo del artículo 17 de la ley de bancos (antigua ley de Bancos D. Leg. 770 - concordado con la actual Ley del Sistema Financiero, D. Ley 26702 en su art. 3ro.), que autoriza a las empresas del sistema financiero a fijar libremente las tasas de interés para sus operaciones activas y pasivas, sin observar los límites fijados por el art. 1243 del Código Civil. La venta de cartera se instrumenta en cesión de créditos, acto jurídico que es definido en el código civil en los términos siguientes: "La cesión de derechos comprende la transmisión al cesionario de los privilegios, las garantías (...) así como los accesorios del derecho transmitido...”

Por tal motivo es necesario realizar un análisis lingüístico de la palabra privilegio:

“Exención de una obligación o ventaja exclusiva o especial que goza alguien por concesión de un superior o por determinada circunstancia propia., en tal sentido tiene como finalidad con la cesión que el cedido conserve las características inherentes a los derechos (créditos) que se transfieren, sin que el cambio de acreedor pueda alterar su naturaleza, esto es mantener la tasa de interés fijada como privilegio a la empresa financiera “

En consecuencia, si existen demandas interpuestas sobre los créditos materia de transferencia se deberán presentar escritos a los Juzgados comunicando la cesión y apersonándose el cesionario.

*Ver en Anexo el modelo

\subsection{Legislación Nacional aplicable}

Del análisis de la legislación Nacional se desprende una serie de dispositivos jurídicos que servirán para el buen desarrollo del contrato de cesión de créditos en el Sistema Financiero, en consecuencia, las normas que son materia del tema de la presente investigación son:

a) Ley del Sistema Financiero, del Sistema de Seguros y Orgánica de la Superintendencia de Banca y Seguros (Ley No.26702).

b) Código Civil (artículos No 1206 al 1213).

c) Circular SBS NoB-1947-93 (5/11/93), Venta de Cartera.

d) Circular SBS NoB-1974-95 (26/07/95), Operaciones de cesión de derechos.

e) Oficio Circular No1045-98, Ventas de Cartera.

f) Oficio Circular No1465-98, Ventas de cartera. 


\section{DERECHO COMPARADO}

\subsection{Algunas legislaciones que la contemplan}

Básicamente las legislaciones extranjeras, haciendo uso del derecho comparado.

En Chile no se permite que una empresa financiera transfiera su cartera a terceros, solo se permite que se transfiera a otra empresa del Sistema Financiero.

Hay tres Códigos Civiles que legislan expresamente sobre la cesión del contrato o cesión de posición contractual. Son los Códigos Civiles de Italia, de Portugal y el de Holanda.

El Código Civil Italiano de 1942 lo denomina de la cesión del contrato, dedica al tema cinco artículos que se ocupan de las relaciones entre el cedido y cedente, de las relaciones entre el cedido y cesionario, y las relaciones entre el cedente y cesionario.

En dicha legislación indica que si en todos los documentos que se ceden se coloca las cláusulas a la orden, la sustitución del cedente al cesionario se hará en virtud de un simple endoso. Asimismo, es interesante la reserva que puede hacer el cedido de no liberar al cedente, eventualidad en la cual podrá accionar contra éste cuando el cesionario no cumpla las obligaciones asumidas.

En el Código Civil Portugués de 1966, el enfoque es más civilista que del italiano, pues se ocupa fundamentalmente de las vinculaciones entre las tres partes que intervienen en la cesión, sin contemplar la posibilidad de circular el contrato mediante el endoso.

El Código Civil Holandés se ocupa de la cesión de contrato, indicando que importa la cesión de derechos y obligaciones.

- Ley 26702 definidas en el numeral 8 del artículo 282 (Ley General del Sistema Financiero) como aquellas cuya especialidad consiste en la adquisición de facturas conformadas, títulos valores y en general cualquier valor mobiliario representativo de deuda y la Resolución SBS 1021-98, Reglamento de factoring Resolución SBS No1021-98 del 3/10/98, descuento y empresas de factoring. A través de la Resolución No1021-98 del 3/10/98, la S.B.S , aprobó el reglamento de factoring, descuento y empresas de factoring, definiéndolo como la operación mediante la cual el factor adquiere a título oneroso de una persona natural o jurídica, instrumentos de contenido crediticio, pudiendo además prestarle servicios adicionales a cambio de una retribución. Los instrumentos crediticios pueden ser facturas y títulos valores representativos de deuda y de libre disposición del cliente. El factoring se perfecciona mediante contrato escrito que suscribe el cliente con el factor, que es una sociedad anónima autorizada por la S.B.S. Los servicios adicionales que pueden prestar las empresas de factoring son de investigación e información comercial, gestión y cobranza, servicios contables, asesoría y estudios de

6. Resolución No1021-98 del 3/10/98, la S.B.S 
mercado. Asimismo, según la Circular G-015-98 el capital mínimo para estas empresas deberá ser S/.1 537095,00 .

- Como podemos observar el Reglamento establece un contenido mínimo al contrato de factoring. En primer lugar, queda descartada la posibilidad de la sola función de gestión sin transmisión de créditos, ya que esta es una de las características del contrato, de lo contrario el factor no podría correr con los riesgos de la operación si no fuera titular de los documentos de crédito. De manera adicional el factor puede prestar servicios de manera adicional a la obligación principal como el de asesoría y financiamiento a cambio de una redistribución. Uno de los primeros aspectos que se deben tomar en cuenta consiste en la naturaleza de los títulos de crédito que el cliente transfiere al factor. Según el reglamento, debemos entender que no hace una enumeración taxativa de la clase de instrumentos de crédito que se pueden transferir al factor. En todo caso hace referencia a su naturaleza jurídica seńalando que deben tratarse de un valor mobiliario representativo de deuda.

- Las transferencias de los títulos de crédito se transfieren en propiedad al cedido a título oneroso, de acuerdo a la naturaleza de estos documentos. En caso de los títulos valores la transferencia se hace mediante el endoso, existiendo tres clases de endoso:

1. En propiedad.

2. En procuración.

3. En garantía.

En el caso de la factura conformada, según el artículo 237 de la Ley del Sistema Financiero le atribuye la naturaleza jurídica de título valor y como forma de transmisión a terceros establece el endoso. En este sentido debemos entender que el endoso se rige por la única norma que establece sus reglas: La ley de títulos valores, por lo tanto el endoso debe ser en propiedad. El art. 237 establece que la factura conformada es un título valor que representa bienes entregados y no pagados, debidamente suscrita por el deudor en señal de conformidad en cuanto a la entrega de los bienes allí precisados, su valor y la fecha de pago de la factura. La factura conformada es emitida por el acreedor y puede ser endosada a tercero.

- Convenio de Unidroit sobre factoring internacional: convocada por el Gobierno Canadiense y celebrada en Ottawa del 9 al 28 de mayo de 19887, y quedó abierta a la firma de todos los Estados, en consecuencia, Francia, Nigeria, Italia, Hungría ratificaron su adhesión.

4.2 El contrato de Cesión y el Impuesto General a las Ventas

Hasta antes de la dación del D. Leg. 821, Ley del I.G.V. actualmente vigente, prevalecía el criterio de que la cesión de créditos implicaba la transferencia de bienes intangibles y que dicha transferencia

7. Convenio de Unidroit sobre factoring internacional, Otawa 1988. 
no estaba comprendida dentro de los alcances de I.G.V. Bajo este supuesto, existía duda en cuanto al tratamiento de estas transferencias para efectos del cálculo de la prorrata aplicable para la determinación del crédito fiscal proveniente de las adquisiciones de bienes y servicios utilizados en la realización de operaciones gravadas y no gravadas con el impuesto.

Con la intención de aclarar la duda existente, la Quinta disposición Transitoria del D. Leg 821, precisó que las operaciones de CESIÓN DE CRÉDITOS tienen el carácter de prestación de servicios financieros a cambio de los cuales el factor recibe una comisión y la transferencia en propiedad en facturas. La citada transferencia y correspondiente cesión de créditos no constituye venta ni prestación de servicios. Por su lado la Quinta disposición final del D.S. No136-96-EF del 31.12.96, precisó que el monto percibido por el transferente de las facturas no debía incluirse dentro del cálculo de la prorrata para la determinación del crédito fiscal.

Asimismo, conviene manifestar que la factura comercial no es un título valor que puede ser objeto de transferencia, siendo independiente y perfectamente diferenciable del crédito que pudiera originar la operación comercial que dio origen a su emisión. Desde nuestro punto de vista, mal puede concebirse la facultad de disponer en propiedad de las facturas comerciales, cuando el numeral 7 del art. 87 del Código Tributario. obliga a conservar los documentos y antecedentes de las operaciones o situaciones que constituyan hechos generadores de obligaciones tributarias mientras el tributo no este prescrito; y el Reglamento de Comprobantes de pago precisa el destino que debe darse al original y cada una de las copias de los mencionados comprobantes. Por tanto, el concepto de cesión de créditos para el IGV es sumamente restringido, y más aún de la cesión de créditos.

Los adquirientes de estos créditos tienen el temor que la Administración Tributaria califique a estas cesiones sujetas al IGV por ser prestación de servicios.

Por regla general la cesión de créditos no debe ser incluida dentro del campo de aplicación del IGV, por cuanto ello incrementará los gastos de control administrativo del fisco sin generar un mayor efecto recaudatorio. En operaciones efectuadas al crédito, el objetivo de gravar al consumidor con la tasa del $18 \%$ sobre el valor de la operación ya está cumplido. La cesión del crédito originado en ella no supone un valor agregado gravable en la cadena de producción y producción que ya habría alcanzado su etapa final de ésta manera que, de ser aplicable el IGV, éste se trasladaría al transferente descontándose del valor del crédito adquirido y sería a su vez aplicado por tal transferente como crédito fiscal, con lo cual el efecto recaudatorio sería nulo. En consistencia, creo que el cesión de créditos podría gravarse con el IGV sólo por el diferencial entre el valor nominal y el valor de transferencia, cuando económicamente materialice un servicio de financiamiento prestado por el adquiriente, esto es cuando garantizando la cobranza del crédito cedido, la responsabilidad del transferente se hiciera efectiva frente al adquiriente con ocasión de incobrabilidad del deudor; y cuando no habiéndose garantizado la cobranza del crédito, la incobrabilidad al deudor determine la recompra del crédito por el transferente, a mayor valor del que lo hubiera adquirido. 
Asimismo, por razones prácticas, tratándose de cesiones de crédito que conllevarán la prestación de servicios complementarios, la diferencia entre el valor de transferencia del crédito y su valor nominal constituiría una prestación de servicios gravable con el IGV, salvo que se discriminara el importe que retribuye los servicios del valor de transferencia de los créditos, en cuyo caso sólo se gravarían los servicios.

4.2.1 Consideraciones de importancia, en la formación y proceso de una empresa de cobranzas cuales son las implicancias jurídicas

Haciendo un paralelo en el Mercado actual, podremos citar como ejemplo una Empresa de Cobranzas que se dedica a la prestación de servicios de administración de riesgo de terceros y de cartera propia; siendo esta última generada por la compra de cartera a Instituciones bancarias (en adelante, el Banco), la operativa en términos genéricos sería:

a) La adquisición de la cartera se efectúa mediante la celebración de un contrato de cesión de créditos y addendum, que son presentados a la Superintendencia de Banca y Seguros (en adelante, la SBS), y que conllevan la transferencia de todos los accesorios de los créditos, ésta se efectúa sin recurso, de manera que el riesgo de insolvencia es totalmente asumido por la empresa de cobranzas.

b) La transferencia de la cartera conlleva el endose en propiedad de documentos crediticios tales como, pagarés, letras de cambio, liquidaciones de saldo deudor, etc. Tratándose de los pagarés, éstos comprenden el capital insoluto y los intereses compensatorios correspondientes, provenientes de la actividad crediticia propia del Banco; no así, los intereses moratorios ni los gastos de cobranza.

c) La compra de cartera se realiza a valor comercial, previa tasación consensual de las partes, determinándose en un porcentaje insoluto de los créditos.

En tanto los créditos cedidos tienen un plazo de pago determinado. La empresa de Cobranzas muchas veces concede la prórroga del mismo, en ejercicio de la facultad contemplada en las Cláusulas Contractuales que se pacten celebrados por el Banco y los clientes, que son fuente de los créditos cedidos.

\section{ANÁLISIS PRELIMINARES SOBRE FACTORING Y LA CESIÓN DE CRÉDITOS}

1. Antes de analizar la incidencia del IGV en las adquisiciones de cartera realizadas por la empresa de Cobranzas, consideramos conveniente deslindar las diferencias y semejanzas existentes entre la cesión de crédito y las operaciones de factoring.

a) Cesión de créditos

Conforme el artículo 1206 del Código Civil, la cesión es el acto de disposición en virtud del cual el cedente transmite al cesionario el derecho a exigir la prestación a cargo de su deudor, que se ha obligado a transferir por un título distinto. La cesión puede hacerse aún sin el asentimiento del deudor. 
Conforme al artículo 1212 del Código, el cedente está obligado a garantizar la existencia y exigibilidad del derecho cedido, salvo pacto distinto. Esta norma se encuentra dirigida a propiciar (cabe pacto en contrato) la obligación del cedente de asegurar la existencia del derecho (bien intangible) que transfiere, no así la cobranza efectiva del derecho cedido que queda a riesgo del adquiriente.

Establece el artículo 1213 del mencionado cuerpo legal, que el cedente no está obligado a garantizar la solvencia del deudor, pero si lo hace, responde dentro de los límites de cuanto ha recibido y queda obligado al pago de los intereses y al reembolso de los gastos de la cesión y de los que el cesionario haya realizado para ejecutar al deudor, salvo pacto distinto. Esta norma propicia la transferencia del riesgo de la cobranza al cesionario. En caso de pacto en contrario, se propicia la limitación de la responsabilidad del cedente al monto recibido por la cesión del crédito, más intereses y gastos. Sin embargo, como quiera que esto último admite también pacto en contrario, en determinados casos la cesión de derechos puede llegar a adquirir económicamente las características propias de un financiamiento ordinario con garantía de determinados créditos.

De las normas expuestas queda claro que la cesión de derechos es una especie de acto jurídico que puede adoptar muchas modalidades; de manera que, desde un punto de vista económico y según las condiciones pactadas por las partes, podría configurar:

- Una operación de enajenación definitiva de créditos sujeta a saneamiento (en caso de garantizarse la existencia y exigibilidad del crédito cedido) o no sujeta a saneamiento (en caso la existencia y exigibilidad del crédito no fuera garantizada); o,

- Una operación de financiamiento, que se materializa en caso la transferencia del crédito se realizara con recurso (con garantía de la cobranza del crédito) y la responsabilidad del cedente se hiciera efectiva con ocasión de la incobrabilidad al deudor.

Cabe destacar que este último supuesto de financiamiento del cesionario al cedente, no se configuraría entre la empresa de cobranzas y el Banco, puesto que la cesión de los créditos es efectuada sin recurso, debiéndose señalar expresamente en el Contrato correspondiente que bajo ningún supuesto el Banco readquirirá la Cartera transferida la empresa de cobranzas, ni tendrá responsabilidad alguna por su incobrabilidad o los gastos de cobranza que se generen.

b) Contrato de factoring

El contrato de factoring (de responsión o factoraje) es un contrato por el cual un comerciante o empresa (factorado o cliente) encarga a otra entidad (factor), el manejo de su facturación, mediante la transmisión de sus créditos frente a terceros. En principio, el contrato de factoring se relaciona directamente con los servicios que un banco o entidad especializada puede prestar a sus clientes, en función de los créditos de los cuales éstos son titulares como resultado de su actividad mercantil. 
Por el factoring, el cliente cede sus derechos de crédito obtenidos en su actividad mercantil (operaciones normalmente reflejados en facturas) al factor, a fin de que éste último le adelante su pago. El factor queda obligado a adquirir todos los créditos que se originen normalmente y de manera constante en el negocio del cliente, durante un tiempo expresamente convenido; pudiendo reservarse la facultad de seleccionar tales créditos y de abonar los mismos a un precio fijo determinado en base a una proporción sobre su valor nominal. Por regla general, el factor se obliga a la prestación de determinados servicios (básicamente administrativos), quedando los riesgos de cobrabilidad a cargo del factor.

El contrato de factoring puede asumir diversas modalidades, entre las cuales podemos mencionar aquellas que suponen la transferencia de créditos con o sin recurso, según se garantice la cobrabilidad de las acreencias; y las transferencias con recurso y de servicios de gestión y de cobranza al cliente o no, según medie una simple representación para efectos de cobranza o no.

c) Diferencias entre la cesión de créditos y el factoring

Conforme a su desarrollo doctrinal, no toda operación de factoring supone una cesión de créditos, puesto que puede celebrarse un contrato de factoring en el que no medie transferencia de créditos sino únicamente la prestación de servicios de gestión de cobranza en representación del titular original de los créditos.

Por su lado, tratándose de aquellos contratos de factoring que suponen la transferencia de créditos del cliente a favor, el factoring resulta siendo una especie de la cesión de derechos crediticios:

- Mientras el factoring está normalmente referido a la transferencia, con o sin recurso, de créditos originados en el normal desarrollo de las operaciones comerciales de un negocio; la cesión puede versar sobre créditos originados en operaciones o ingresos extraordinarios y no necesariamente comerciales.

- Mientras el factoring supone como regla general la prestación de servicios administrativos relacionados al manejo de la cartera de clientes, la cesión supone únicamente la transferencia de un derecho sin prestaciones conexas.

- Mientras el factoring involucra la transferencia del conjunto de créditos originados en el desarrollo ordinario de las operaciones del negocio, la cesión de derechos puede constituir un acto aislado o esporádico, tanto respecto del cedente como del cesionario.

\section{Regulación del factoring en materia del IGV}

Debemos destacar que para el análisis de la incidencia del IGV en las transferencias de cartera efectuadas por el Banco a favor de adquiriente, que trataremos en los puntos siguientes del presente informe, partimos de la presunción de que los créditos cedidos no se originan ni respaldan en la emisión de facturas conformadas, ni conllevan la prestación de servicios complementarios como son los de administración de cartera, selección de clientela, teneduría de libros contables, entre otros. 
a) Quinta disposición Complementaria y Transitoria de la Ley del IGV

La Quinta disposición Complementaria y Transitoria del Decreto Legislativo 821 -Ley del IGV actualmente vigente, precisó que las operaciones de factoring tienen el carácter de prestación de servicios financieros a cambio de los cuales, el factor recibe una comisión y la transferencia en propiedad de facturas. La citada transferencia y correspondiente cesión de créditos no constituye venta de bienes ni prestación de servicios.

Esta precisión citada supone una definición indirecta del concepto del factoring regulado por la ley del IGV, de acuerdo a la cual, la transferencia en propiedad de facturas es un requisito sustancial para la configuración de una operación de factoring.

Sin embargo, jurídicamente, salvo el caso de las facturas conformadas establecidas por el artículo 237 de la Ley $26702^{8}$, las facturas comerciales (así como los demás comprobantes de pago) no son títulos valores que puedan ser objeto de transferencia en propiedad, ni son representativas de la existencia y disposición de un crédito. En efecto, desde un punto de vista jurídico, el crédito de una determinada operación y el comprobante de pago (factura comercial) que la sustente, son objeto jurídicos independientes y perfectamente diferenciables; la factura no contiene ni representa al crédito correlativo, aun cuando se originen en una misma operación comercial.

Debe tenerse en cuenta que de conformidad con el artículo 923 del Código Civil, la propiedad es el poder jurídico que permite usar, disfrutar, disponer y reivindicar un bien. Mal podemos concebir la facultad de transferir la propiedad de las facturas comerciales (y demás comprobantes de pago) en una operación de factoring, cuando el numeral 7 del artículo 87 del Código Tributario, obliga a conservar los libros y registros, así como los documentos (entre ellos, los comprobantes de pago) y antecedentes de las operaciones o situaciones que constituyan hechos generadores de obligaciones tributarias, mientras el tributo no esté prescrito; y, el Reglamento de Comprobantes de Pago, aprobado por Resolución de Superintendencia 018-97/SUNAT, precisa el destino que debe darse al original y cada una de las copias de los mencionados comprobantes.

En atención a lo expuesto, es nuestra opinión que el concepto de factoring vigente para efectos del IGV es mucho más restringido que el concepto doctrinal de factoring y más restringido que el de la cesión de créditos. Desde un punto de vista jurídico, el mencionado concepto legal sólo tiene aplicación real en la actualidad respecto del endoso en propiedad de las facturas conformadas, por lo que fuera de este supuesto, no encontramos en nuestra legislación solución a la incertidumbre jurídica

8. Las facturas conformadas son títulos valores causales y nominativos, señalan en detalle los bienes objeto de comercio al crédito cuyo pago total o parcial representan, constituyen constancia de recepción de dichos bienes por el deudor y representan un derecho real de garantía sobre los bienes descritos en el mismo título. Por serles aplicables las mismas reglas de la letra de cambio, las facturas conformadas son transferibles por endoso en propiedad, en garantía y en procuración. 
existente en torno a la cesión de créditos en cualquiera de sus modalidades (incluido aquellas que suponen operaciones de factoring, bajo su acepción doctrinal).

Atendiendo al principio de legalidad que informa el sistema tributario nacional, consagrado constitucionalmente por el artículo 79 de la Constitución y recogido por la Norma IV y el tercer párrafo de la Norma VIII del Título Preliminar del Código Tributario; concluimos que en atención a lo dispuesto por la Quinta Disposición Complementaria y Final del Decreto Legislativo 821:

- La operación que regula la Ley del IGV bajo la denominación de factoring, sólo resulta de aplicación a la transferencia (endoso) en propiedad de facturas conformadas;

- La denominada operación de factoring regulada por la Ley del IGV es de concepto mucho más restringido que el de la cesión de créditos regulada por el Código Civil y que la definición doctrinal del contrato de factoring, en cualquiera de sus modalidades.

b) Normas Generales de la Ley del IGV

Vista la inaplicación de las disposiciones de la Quinta Disposición Transitoria y Complementaria de la Ley del IGV a las operaciones de cesión de créditos efectuadas por Bancos a favor de Empresas de Cobranza, encontramos que los efectos del referido Impuesto en las operaciones comentadas deben ser dilucidados por aplicación de las normas generales del Decreto Legislativo 821.

Para los Banco, la cesión de los créditos tiene por único objeto posibilitar la percepción del ingreso devengado en una previa operación comercial, que se ha encontrado oportunamente sujeta a las reglas del Impuesto. Por su naturaleza, la transferencia del crédito no constituye la transferencia en propiedad (los derechos personales no soportan los derechos reales como el de propiedad, su transferencia importa la cesión de su titularidad) de un bien mueble (el crédito no es un bien corporal, ni uno de los bienes incorporales incluidos en la definición legal prevista en el Decreto Legislativo 821). Asimismo, la cesión del crédito no supone la prestación de un servicio retribuido, pues sólo conlleva la enajenación de un derecho personal, y en algunos casos, que detallaremos más adelante, el aprovechamiento de un servicio de financiamiento.

En tal sentido, consideramos que para efectos del Banco cedente (y sin perjuicio de las exoneraciones que lo favorecen), la transferencia de créditos no tiene incidencia en el IGV. Este criterio, coincide con el vertido en el Decreto Legislativo 821 al regular la transferencia en propiedad de facturas, cuando establece que ésta no constituye venta de bienes muebles ni prestación de servicios, y con el Decreto Supremo 136-96-EF, cuando dispone la neutralidad de estas operaciones en el cómputo de la prorrata del crédito fiscal.

Para las empresas de Cobranza adquirientes de tales acreencias, la adquisición de los créditos no constituye más que la realización de una inversión con fines especulativos ${ }^{9}$, efectuada bajo la expectativa

9. Téngase en cuenta, la precisión efectuada al inicio del presente numeral, para efectos del desarrollo del presente análisis. 
de obtener una ganancia al momento de su realización (transferencia a un tercero o cobro del crédito), vía la subrogación en los derechos del cedente a cambio del pago de un precio o retribución. La compra de los créditos se realiza normalmente a un precio menor al de su valor nominal, fijado en atención a la ponderación del factor tiempo y del factor riesgo, los cuales pueden variar de una operación a otra según las condiciones de la misma (posibilidad de efectuar pre-pagos, solvencia y reputación del deudor, entre otros).

La adquisición de créditos no está prevista entre los hechos gravados por el artículo 1 del Decreto Legislativo 821, no siendo venta de bienes, prestación de servicios, primera venta de inmuebles, contrato de construcción, ni importación de bienes. En tal sentido, opinamos que, para la empresa adquiriente cesionaria, la sola adquisición de los créditos no constituye un hecho gravado con el IGV.

Efectuado el análisis que antecede, es importante formularnos las siguientes interrogantes y sus respuestas:

1.- ¿Puede la empresa adquiriente cobrar los intereses moratorios, gastos de cobranza, costas y costos judiciales, de ser el caso?

En virtud del contrato de cesión de créditos la empresa adquiriente se convierte en titular de los créditos que le son transferidos, junto con los accesorios del mismo. En tal sentido, se encuentran facultados a cobrar el capital adeudado, más los intereses compensatorios y moratorios y los gastos de cobranza que resultan accesorios del mismo.

2.- ¿Estará el adquiriente sujeto o no al pago del IGV u otro impuesto?

Mientras el titular del crédito haya sido el Banco, la retribución correspondiente se habrá encontrado exonerada del IGV en aplicación del artículo 5 y el numeral I del Apéndice II, conforme a los cuales se encuentran exonerados del Impuesto los servicios de créditos, entendidos como los ingresos percibidos por los Bancos e Instituciones Financieras y crediticias, por concepto de comisiones e intereses derivados de las operaciones propias de estas empresas. Sin embargo, a partir del momento en que se transfiere la titularidad del crédito por efectos de la cesión, la empresa adquiriente (como nueva titular del mismo) se convierte en la titular (prestadora) del servicio de financiamiento, de manera tal, que los intereses y cargos accesorios del capital insoluto que se devenguen con posterioridad a la cesión lo serán a favor del adquiriente a título de retribución. Como quiera que el adquiriente no reúne las condiciones para gozar de la exoneración que, si beneficia al Banco cedente del crédito, los ingresos generados a partir de la fecha de la cesión se encontrarán gravados con el IGV en cabeza del adquiriente.

En nuestra opinión, la circunstancia de que la exoneración haga referencia a los ingresos "percibidos" por los Bancos, no determina que el adquiriente deba encontrarse gravada por los intereses devengados antes de la cesión y que por encontrarse insolutos sean comprendidos en el crédito transferidos a el adquiriente. En efecto, con anterioridad a la cesión habrá sido el Banco quién habrá prestado el servicio 
de financiamiento; la calidad de prestador el servicio sólo podrá ser imputada a el adquiriente a partir de la fecha de transferencia del crédito, y sólo a partir de dicho momento, los intereses generados podrán considerarse retribución gravable del adquiriente.

Desde un punto de vista tributario, el adquiriente deberá emitir comprobantes de pago a favor del deudor por los intereses compensatorios y moratorios y gastos de cobranza que se devenguen en su favor. Si el Banco hubiera anticipado la facturación de tales importes, deberá emitir las correspondientes notas de crédito a fin de evitar el doble registro de un mismo concepto.

Finalmente, cabe señalar que el Tribunal Fiscal, mediante RTF-No.466-3-97 del 14.4.97, ha establecido que, tratándose de préstamos sujetos a plazo y a una tasa de interés determinada, el importe de los intereses integra la base imponible de los servicios de financiamiento por resultar plenamente determinables, debiendo ser incluidos en la facturación correspondiente desde un inicio. Dicha resolución se fundamenta en el artículo 14 de la Ley el IGV, que establece que el valor de la retribución, que constituye la base de cálculo del referido impuesto, incluye a los cargos que se efectúen por separado de aquel y aun cuando se originen en la prestación de servicios complementarios, en intereses devengados por el precio no pagado o en gastos de financiación de la operación; así como en el numeral 9 del artículo 5 del Reglamento de la referida Ley, que precisa que cuando se efectúen cargos adicionales a la prestación de servicios gravados, los mismos integrarán la base imponible del IGV en el mes en que sean determinables o en el que sean pagados, lo que ocurra primero.

En nuestra opinión, la mencionada resolución no interfiere con las conclusiones vertidas en los párrafos anteriores, por encontrarse referida al caso de los intereses que se devengan con carácter accesorio respecto de obligaciones comerciales, pero no respecto de aquellos intereses que se devengan con carácter principal como contraprestación de un servicio de financiamiento.

3.- ¿Se podrá trasladar al cliente deudor del crédito el $18 \%$ por concepto del IGV?

El adquiriente podrá trasladar al cliente deudor el IGV que grave los intereses y demás conceptos que se devenguen a su favor a partir de la fecha de la cesión del crédito, al amparo del tercer párrafo del artículo 38 del Decreto Legislativo 821, conforme al cual, el usuario del servicio se encuentra obligado a aceptar el traslado del referido impuesto.

¿El adquiriente puede acordar con el cliente tomar un seguro de desgravamen por el plazo de refinanciamiento que exceda el plazo del crédito original, estando sujeto a Impuesto?

El adquiriente se encuentra facultado a prorrogar el plazo originalmente previsto para el pago del capital sin que ello suponga una novación de la obligación, esto es, la extinción de la obligación primigenia por efecto de su sustitución por una diferente. En efecto, el plazo es una modalidad del contrato de préstamo cuyas condiciones se mantienen vigentes, pudiendo ser prorrogado por acuerdo de las partes, sin que ello suponga la constitución de una nueva relación obligacional distinta a la que existía entre el cliente y el Banco. 
En tanto el contrato de préstamo conlleva la obligación de contratar un seguro de vida en beneficio del acreedor (ahora el adquiriente) por un monto que cubra el total de las cuotas en que se descompone el crédito, resulta natural que al extenderse el número e importe de las cuotas por efecto de la prórroga y consiguiente incremento de intereses devengables, al pactarse dicha prórroga se estipule la obligación de extender la cobertura del seguro de vida en el plazo e importes que correspondan.

El artículo 5 y el numeral 8 del Apéndice II de la Ley del IGV exoneran del referido Impuesto a las Pólizas de seguro de vida emitidas por compañías de seguros constituidas en el Perú, de acuerdo a las normas de la SBS, siempre que el comprobante de pago sea expedido a favor de personas naturales residentes en el Perú. Nótese que esta última condición no se refiere al beneficiario de la póliza que podría ser el propio adquiriente.

Si el adquiriente se viera en la obligación de gestionar la mencionada póliza y cuidara que los comprobantes de pago por concepto de las primas pagadas fueran emitidas a nombre de la persona natural deudora del crédito, éstas se encontrarán exoneradas del IGV, siempre que dicha persona fuera residente en el país. En este caso, el adquiriente podrá cobrar el reembolso correspondiente libre del IGV.

$\mathrm{Si}$, por el contrario, los comprobantes de pago de las primas mencionadas fueran emitidos a nombre del adquiriente, ésta se verá obligada a facturarlas al deudor, incorporándolos dentro de la base de cálculo del IGV, en aplicación del artículo 14 de la Ley del IGV conforme al cual, los gastos realizados por cuenta del usuario del servicio forman parte de la base imponible cuando consten en. el respectivo comprobante de pago emitido a nombre de quien presta servicio Como quiera que el IGV es trasladable al cliente, el sobrecosto del Impuesto perjudicaría al cliente deudor y no ha el adquiriente salvo que la deuda resultara siendo incobrable.

4.- ¿El adquiriente tiene obligación de expedir comprobantes de pago a los deudos de los créditos cedidos por el Banco, por los montos de las recuperaciones o por los montos que excedan por concepto de intereses moratorios, gastos de cobranza, costos y costas judiciales?

Como ha sido señalado en el numeral 1 anterior, el adquiriente deberá emitir comprobantes de pago a favor del deudor por los intereses compensatorios y moratorios y gastos de cobranza, que se devenguen en su favor a partir de la fecha de celebración de la cesión y correspondiente adquisición del crédito.

Con relación a las recuperaciones y costas del juicio, debemos indicarles lo siguiente:

a) La devolución del capital no es materia de facturación, sino sólo los intereses que constituyen la contraprestación.

b) Es el Banco el que se encuentra en la obligación de emitir comprobantes de pago por los intereses que se hayan devengado a su favor con anterioridad a la cesión del crédito. 
c) La percepción del capital y de los intereses devengados con anterioridad a la cesión del crédito no obligarán a el adquiriente a emitir comprobantes de pago, considerando lo expuesto en los literales precedentes.

d) Las costas judiciales son determinadas por el juez en el procedimiento de cobranza correspondiente, las que en caso de resultar siendo de cargo del deudor del crédito cedido, podrán ser deducidas por éste en mérito al documento (recibo) especial que para dicho propósito emita el juzgado correspondiente.

5.- Si el adquiriente, en virtud del contrato, varia las condiciones del crédito en cuanto al monto y plazo aplicables, por efectos de refinanciamiento, ¿tendrá derecho a cobrar la tasa de interés compensatorio y moratorio y demás conceptos, una vez cedido el crédito? Si tales montos exceden del valor final consignado en el pagaré bancario ¿qué obligaciones tributarias generarían?

Como ha sido señalado anteriormente, la transferencia del crédito supone la de todos sus accesorios. El pacto de una prórroga en el plazo originalmente previsto en el contrato no determina la sustitución de la obligación original por una nueva (novación) considerando que el plazo originalmente previsto constituye una modalidad a la que se ha sujetado la obligación de pago del capital prestado. No obstante, lo indicado, consideramos conveniente que se deje constancia de que la prórroga convenida no produce la novación de la deuda original.

La referida prórroga tendrá por efecto ampliar el número de cuotas de pago inicialmente previstas, mientras que la generación de mayores intereses es una consecuencia natural de la prórroga que fuera convenida. Tratándose del mismo crédito cedido por el Banco, el adquiriente se encontrará facultado a cobrar los intereses compensatorios y moratorios y demás conceptos que se devenguen a partir de la fecha de cesión, además de aquellos que ya se encontraran comprendidos en el crédito que le hubiera sido seguido.

Con relación a los efectos tributarios correspondientes a estos cobros, nos remitimos a lo expuesto en el numeral 1 anterior.

6.- ¿Podrán los Bancos llenar los pagarés considerando como valor final de la deuda el importe del capital e intereses moratorios y gastos de cobranza devengados hasta el momento de efectuarse la cesión de los créditos?

En virtud de la cláusula tercera del contrato privado de crédito y de otorgamiento de garantía, los deudores suscriben Pagarés a la vista, autorizando su emisión incompleta y facultando al Banco, en armonía con lo dispuesto por la Circular SBS No.1664-83-EFC/97.10, para que lo complete en caso de incumplimiento en el pago oportuno de una o más cuotas, expresando en el mencionado pagaré el saldo de su obligación.

La cláusula sexta del mencionado contrato establece que a partir de la fecha de vencimiento de cada cuota, el crédito devengará, además de los intereses compensatorios pactados, el interés moratorio 
y los gastos de cobranzas que tenga establecido el Banco para esta clase de créditos; siendo la mora automática.

Asimismo, la cláusula cuarta del contrato establece que la falta de pago oportuno de una o más cuotas en las que está dividido el crédito, dará derecho al Banco a dar por vencidos todos los plazos y en consecuencia a exigirle al deudor el pago total del crédito, sin perjuicio de completar el Pagaré, efectuar su protesto e iniciar las acciones pertinentes para el cobro del íntegro del crédito, sus intereses compensatorios, moratorios, gastos de cobranza, costos y costas.

De las cláusulas citadas tenemos que, considerando la mora automática por el incumplimiento en el pago oportuno de las cuotas, la cual otorga derecho al cobro de intereses moratorios y gastos de cobranza, así como la facultad de dar por vencidos todos los plazos ; tratándose de deudas morosas, el Banco se encontrará en la facultad de completar el Pagaré por el saldo deudor de la obligación que estará compuesto por el capital insoluto, así como por los intereses compensatorios y moratorios y los gastos, devengados e incurridos hasta la fecha de cesión del crédito moroso correspondiente.

Como es natural, los Bancos se encontrarán impedidos de incluir en el pagaré cualquier concepto no devengado a su favor a la fecha de la cesión y que a partir de tal fecha pueda devengarse a favor del adquiriente, en su calidad de nuevo acreedor.

7.- ¿Podría el adquiriente utilizar el sistema de contabilidad del Banco para efectos del cálculo de la recuperación de las deudas; esto es, distinguiendo el capital, los intereses devengados, el capital inicial de la compra y los generados a partir de ella? ¿Existen recomendaciones adicionales para un transparente manejo de estas compras?

Si bien no existe impedimento legal alguno para que el Banco colabore con el cálculo de los intereses y cargos que se devenguen respecto de los créditos cedidos, debe tenerse en cuenta lo siguiente:

a) Por ser el adquiriente por lo general una empresa generadora de rentas de tercera categoría que obtiene más de 100 UITs de ingresos brutos anuales, se encuentra en la obligación de llevar contabilidad completa. Asimismo, por ser sujeto del Impuesto a la Renta y del IGV, se encuentra obligada a registrar todas y cada una de las operaciones de adquisición de cartera y de financiamiento que realiza. Si bien tal registro de operaciones podría basarse en la información que le fuera proporcionada por el Banco, adquiriente será responsable de la verificación de la exactitud de la misma.

b) La contabilización de los créditos cedidos podría ser considerado por la Administración Tributaria, como la prestación de un servicio gratuito a favor del adquiriente y en tal sentido, computable como operación no gravada para efectos del cálculo de la prorrata para la determinación del crédito fiscal del Banco.

De otro lado, debemos llamar su atención acerca de la facultad de los deudores de los créditos de efectuar sus pagos en el Banco, puesto que ello supondría la percepción de la retribución del adquiriente 
y obligaría a esta a entregar en dicho momento los comprobantes de pago correspondientes. Nótese que la falta de otorgamiento de los mismos constituye infracción formal que se encuentra sancionada con cierre de local.

\section{CONCLUSIONES}

- Las Circulares y Oficios Circulares que emite la Superintendencia de Banca y Seguros sobre el tema de Provisiones, ha generado que la Banco de Consumo en especial, que se dedica a ofrecer productos a personas de bajo extracto social y generalmente lo que ocasiona un alto índice de morosidad, eventualmente un porcentaje de su cartera se castigue, generando más costos al Banco, en vista de ello, estas Empresas cada vez tienen necesidades de transferir su cartera a terceros, trasladando la totalidad del riesgo y dedicándose a ofrecer productos dentro de una política crediticia competitiva.

- Con la cesión y/o transferencia de cartera se intercambia la posición contractual, asumiendo la cedida los derechos, acciones y privilegios de la cedente, en tal sentido produce en el cedente la obligación de colocar al cesionario en la misma posición contractual, la contraprestación del cedido es pagar un precio de acuerdo al análisis de valoración versus el tiempo de recuperación y gastos generales que se requieren para obtener la recuperación efectiva y total. Asimismo, del análisis de la actual Ley del Sistema Financiero (Ley 26702), estás empresas que adquieran cartera pueden encuadrarse, dependiendo de la reglamentación dentro de las empresas de Factoring.

- La contribución de generar empresas que inviertan en este rubro, en base a grandes sumas de inversión para el pago por la compra de capital, infraestructura y contratación de personal.

- Es un contrato financiero, en la cesión de créditos se busca transmitir en forma conjunta los derechos, acciones y privilegios, en ello también se encuentra las obligaciones a través de la unión del traslado de créditos y sus derechos implícitos, con el traslado de obligaciones. La cesión se debe hacer entre el cedente y el cesionario, sin la intervención del cedido, lo único que se exige es una comunicación fehaciente al cedido de dicha cesión, sin necesidad de su consentimiento, ni mucho menos.

- A mi juicio es la transferencia de cartera en la que se intercambia la posición contractual, asumiendo la cedida los derechos, acciones y privilegios de la cedente, en tal sentido produce en el cedente la obligación de colocar al cesionario en la misma posición contractual, la contraprestación del cedido es pagar un precio de acuerdo al análisis de valoración versus el tiempo de recuperación y gastos generales que se requieren para obtener la recuperación efectiva y total.

- La cesión y/o transferencia de cartera que con el mismo se intercambia la posición contractual, asumiendo la cedida los derechos, acciones y privilegios de la cedente, en tal sentido produce en el cedente la obligación de colocar al cesionario en la misma posición contractual, la contraprestación del cedido es pagar un precio de acuerdo al análisis de valoración versus el tiempo de recuperación y gastos generales que se requieren para obtener la recuperación efectiva y total. Asimismo, busco dar soluciones 
al tema investigado, sobre la necesidad de las empresas Financieras de enajenar su cartera dentro de un marco atractivo legal, que permita dar solución a corto plazo, cumpliendo con los mecanismos que establece el régimen jurídico vigente.

\section{REFERENCIAS}

- $\quad$ Avogadro, R. Il Factoring, Cooperación Crediticia, 1980.

- Bermúdez, E. El factoring, nuevas fórmulas de financiación. Madrid: Asociación para el progreso de la Dirección, 1972.

- Castellares Aguilar, Rolando. El contrato de factoring. Congreso Nacional de Derecho Civil y Comercial: 1993, pág. 609 y sgte.

- García Cruces Gonzáles, José Antonio. El Contrato de Factoring. Madrid: Ediciones Tecno, 1990.

- De la Puente y Lavalle, Manuel. Estudios del Contrato Privado. Tomo primero. Lima: Cultural Cuzco, 1983.

- $\quad$ E. Chuliá Vicent - T. Beltrán Alandete, Aspectos jurídicos de distintos contratos atípicos. Barcelona. España: Editorial: Jose María Bosch Editor, 1998.

- Eizaguirre, José María. “Factoring”. Revista de Derecho Mercantil, Na187/188, (enero - junio 1988): pág. 35 y sgte.

- Farina, Juan M. Contratos Comerciales Modernos. B. Aires, Argentina: Editorial Astra 1993.

- Hundskopf, Oswaldo. Derecho Comercial - Nuevas orientaciones y Temas Modernos. Lima, Perú: Universidad de Lima, 1ra Edición, 1989.

- $\quad$ Roca Guillamón, J. El Contrato de factoring y su regulación por el Derecho Privado Español. Madrid: Edersa, 1977.

- Rodríguez Velarde, Javier. Los Contratos Bancarios Modernos.Lima, Perú: Editorial Grijley, 2a Edición, 1995.

- $\quad$ La Convención de Unidriot sobre el factoring Internacional, Ottawa 1988.

- Informativo Caballero Bustamante. "Derecho Comercial". 1. Quincena, octubre de 1998: pág. G-1.

- $\quad$ Ley General del Sistema Financiero - Ley 26702.

- $\quad$ Resolución SBS No1021-98. 
- Diario Gestión / Coyuntura, Sección economía, Lima, miércoles, 1o de abril de 1998.

- El Peruano / Informe - Sección pág. B-7, miércoles 8 de julio de 1998.

- $\quad$ El Peruano / Informe - pág. B-7, viernes 20 de febrero de 1998.

- $\quad$ El Peruano / Informe - pág. B-7, martes 28 de enero de 1997.

- Internet - Poder Legislativo Federal - Código de Comercio - Las cesiones de crédito no endosables.

RECIBIDO: 19/07/2021

APROBADO: 20/10/2021

\section{ANEXO}

* El siguiente es un modelo que deberá presentar la empresa financiera:

....al amparo de lo dispuesto por los artículos $1206^{\circ}$ y ss. del Código Civil, y de lo previsto por el artículo $108^{\circ}$ inc. 3 del Código Procesal Civil, mediante el presente escrito venimos a ceder los derechos y acciones de los que somos titulares en el presente procedimiento a favor de la empresa domiciliada en con RUC No debidamente representada por yyy según poder adjunto, identificado con L.E. No, con domicilio real en y domicilio procesal en ........................., empresa que se sustituye procesalmente en nuestra posición en el proceso como titular de nuestros derechos.

\section{POR TANTO:}

A Ud. Sr. Juez pedimos tener presente lo expuesto y proveer conforme a ley.

OTROSÍ DECIMOS: Que, adjuntamos al presente escrito copia del contrato y addendum de transferencia de cartera celebrado entre y

OTROSÍ DECIMOS: Que, para efectos de dar cumplimiento a lo dispuesto por el art. 1215 del Código Civil, solicitamos se notifique el presente escrito y la resolución que recaiga en él a los demandados. 